\title{
A Comparative Study of the Management Mode of Sino-American Institutions of Higher Learning from the Perspective of the Party-Administrative Power Separation and Operation Mechanism
}

\author{
Qing Xin ${ }^{1}$ \\ ${ }^{1}$ YANGTZE UNIVERSITY
}

\begin{abstract}
In this paper, we research on the higher education management mode of China and America based on the perspective of operation mechanism, separation of school and the government. As the thought of higher education management theory or a form, we jump out of the labyrinth of modernism manages view and the introduction of totally different from the modernist paradigm, from the angle of the theory research of postmodernism manages view. The paper is organized as the follows. In the first section, we generally introduce the basic concepts of higher education management and the relationship of the schools and government. Then, by comparing the pattern of the Chinese and the American, we analyze the difference in detail. Finally, we set up the prospect and the conclusion. In conclusion, our method combines the advantages of the American higher education management model which will be meaningful.
\end{abstract}

Keywords: Higher Education Management; Operation Mechanism; School and the Government.

\section{Introduction}

Higher education management is the whole process of higher education as an object, follow the objective laws of higher education activities, use of modern scientific management theory, principles and methods of the higher education work decision-making plan, organize and implement, to guide, to summarize, maximum limit arouse the enthusiasm of teachers and students, so as to guarantee the higher education goal of activities [1]. Higher education activity itself is more than one structure, multi-factor and multi-level complex activities. The fundamental starting point of the higher education management, it is adapt to the objective facts, for higher education purpose, higher education process, higher education content, higher education method, higher education organization and higher education assessment, and formed by the above factors and higher education quality to conduct a comprehensive management. Only give full play to the functions of each link of higher education, straighten out the various internal and external relations in the process of higher education, is possible to realize the scientific higher education management activities, in order to obtain the desired effect of the higher education quality. As the thoughts of higher education management theory or a form, jump out of the labyrinth of modernism manages view and the introduction of totally different from the modernist paradigm, from the angle of the theory research of postmodernism manages view. Such an earlier article also compared comprehensively introduces the postmodernism manages view.

Although people to the study of postmodernism in full swing, but about the applicability of the postmodern cultural background in China and its trade-off studies in higher education management practice rarely involved. The current of our higher education management should with distinctive flavor of modern management. As a kind of comes from the west, the trend of development in the west, its higher education management in China have reference value, feasibility in China's cultural environment, and which can bring us alert, these 
are all we need to think. Postmodernism, as a kind of social ideological trend, the background is the modernization of reflection and criticism. Mention of modernity, we first think of the human social development process of a natural change, at the same time is also a kind of modernity selection and implementation purposes or goals. Therefore, as a kind of things, the unity of purpose and process of modernization in has made great achievements and development of the material world, and bring people a more efficient and convenient at the same time, also brought mankind into all sorts of trouble which has many side effects [2-3].

Rapid development of computer network, information technology has changed the human concept of time and space, multimedia and virtual technology created has the different virtual world and real world and the center of the artificial intelligence online challenges the job status. Postmodernism is opposed to the thinking mode of binary opposition, dispelling the objectivity of thought, advocated irrationalism. Irrationalism is based on the reflection of traditional rationalism and critical characteristics. But we must see in science and technology behind the high-profile which is the person produces the vital role. People began to reflect on the higher education management mechanism, decentralization, policy guidance, higher education begin to introduce legislation, set up the agency has the basic values of democratic orientation, such as through the higher education management rhyme democratization operation to achieve its aims and objectives. The task of higher education management is reasonable allocation and use of the limited higher education resources, to realize the goal of cultivating more and better talents for the country and creating more and better the purpose of scientific research achievements. In the figure one, we illustrate the basic principles and pattern of higher education management mode visually.

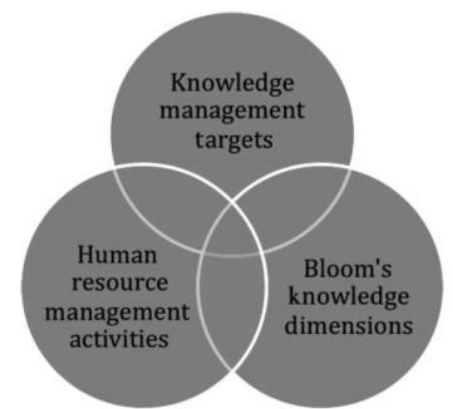

Figure 1. The Basic Principles of Higher education Management Mode

In this paper, we research on the higher education management mode of China and abroad based on the novel perspective of operation mechanism and separation of school and the government. Higher education management mode is under the domination of certain higher education management concept for the realization of specific higher education goals to create a model of higher education management. Pattern is often about the existence of things or movement form made after analyzing abstract theory summary, namely people for a particular purpose, operation, performance or connect with each other to know object character the development trend and mechanism of the a kind of abstract theory description or facsimile. In the next sub-sections, we will discuss the mentioned problems in detail.

\section{The Comparison Research and Discussion}

The Operation Mechanism Comparison Research. At present our country is in a stage of rapid development, especially since the reform and opening, the transformation of economic system has brought to politics, culture and other aspects of the change to the higher education management has brought many new requirements. If the higher education management does not timely adjust to the idea, change the way, will cause the problem. Along with the practice of opening to the outside world and socialist market economy, higher education calls for a more independent management organization. Autonomous management of 
effective implementation needs the support of institutions. But for a long time, our organization is to adapt to the higher education system under the planned economy system, and the set inside the repetition, inseparable, different departments of the power and responsibility consciousness is not clear, management vacancy or repeat, causing idle and waste of resources. Now depends on the implementation of management of higher education in China.

It has been found that the traditional higher education management ignored the democratic factors and join, thought through quantitative management techniques and methods can solve all the problems of higher education system as a political system management of higher education management target, management object and management process, such as lack of system thinking and reflection. It requires that the organization as an open system, can adapt to changes in the environment and requirements in a timely manner. In this case, the hierarchical system of modern organization and mechanical management is difficult to adapt to, on the contrary, flexibility, adaptability and creativity of organization is more in line with the requirements of the environment.

The Separation of School and the Government. Colleges and universities is a talent, knowledge creation and inheritance have gathered important institutions both America and China, the legal basis for the school administration system of separation of powers are related. Schools of higher education of China and the United States government decentralization management mode and its practice have obvious differences. American colleges and universities in addition to the special funds aspects such as scientific research, literature and experimental indirect outside the jurisdiction of the administrative subject to government entities at all levels, almost no direct management by the government, especially the American private colleges and universities is almost free from the government in the private higher education institutions in accordance with the law, even if some related business must deal with the government, also is not the school directly docking with the related functions of the government and its institutions, but by the school board, association of higher education to coordinate. Colleges and universities in the United States since the date of birth, and its funds mainly come from the church group sponsorships, donations and private donations and government funding. In fact, the decentralized and centralized in reality is not semantically couple opposites like that for no reason from centralization to decentralization, also do not like moving an object from one place to another place. In a word, the process of separation of powers is actually a benefit mechanism to balance the problem. Advocates the separation of powers, realize the management center of gravity down, reduce the management level of management which is centralized, need to checks and balances, this is a very normal dynamic equilibrium process of power.

School-based management such as the separation of orientation of higher education reform, have identified the separation will remove inefficient dissecting, improve public school running efficiency of the organization. In practice, however it is not an absolute logic, but wants to be decided according to the specific circumstances. Once power down, you accept problems involving power. The government to the school, school, family and so on separation of powers, empowerment, benefit does not equal power to the receiver, but selective, have preferences. From the point of school choice, both at home and abroad are all the same, a lot of facts show that choosing a naturally not in adverse social group, the domestic economic and social capital is superior, by purchasing or other ways to get better higher education resources away from the status quo, and the other position relatively poor families and students can only continue to accept relatively backward in the existing school higher education. 


\section{The Comparison Research of the China} and America. Marketization and liberalization, privatization and deregulation together form a lot of new liberalism reform of the country's main policies and measures. Under the background of marketization, higher education is more and more reflects the characteristics of the market. In different countries, the main content of the higher education market and the way of formation is not the same. Market is the main power in the higher education in the United States the market mechanism is the basic regulation mechanism of higher education in the United States. In recent years, the strengthening of higher education in the United States market trends, mainly for all kinds of colleges and universities increase tuition fees. Higher education's financial which stress not only promoted the formation of the higher education market, and promote the higher education privatization and accountability, and also to a certain extent promoted the higher education decentralization.

In countries higher education decentralization reform higher education decision-making is by the central level down to local communities and the separation of powers is mainly emphasizes the power of multi-center parents hand namely society parents schools jointly participate in higher education management mechanism of the introduction of market mechanism with market mechanism to break the bureaucrats with private capital to resolve financial crisis higher education improve the quality of higher education. Official separation of powers, refers to the state and other public power body based on the official form of separation of powers, it and on the basis of regional general decentralization and it is a limited form of centralization which is the place that by giving a regional groups with independent legal person qualification and local business, make the local groups have the autonomy of the independent administrative power, so as to realize the separation of local and national affairs, that the state management of state affairs, manage the affairs of the local groups.

Administrative power and academic power balanced power structure mode in traditional universities appear more obvious. Council and council, respectively, as a representative of the administrative power and academic power division is responsible for the management of school affairs together, form the balance of power. Internal power structure in the different focus of the academic power and administrative power which has its complicated historical tradition and social reasons, advantages and disadvantages of the structure patterns are not simple. Is given priority to with administrative power mode is advantageous to the different levels organization strict administrative management, to improve management efficiency and benefit, in a planned way allocation of higher education resources, deficiency is the constraint the freedom of academic staff, will limit the development of disciplines, at the same time can cause the contradiction between the administrative and academic personnel.

The Prospect and Summary. Democratic norms of the operation mechanism of national higher education is only written into law, democracy can reflect the value concept of authority. Democracy only rise, by the laws of the state and has supreme authority in legal cases, in order to achieve the in the dominate position in the country and the higher education system. In modern times, modern times, with the progress of science and technology and productivity, as well as the higher education popularization, the higher education career and school size and an accompanying widening. At the same time, also gradually appeared a full-time higher education management personnel, formed a special higher education management team, as a result, produce the independent form the experience of the higher education management mode. Experience a process of accumulation, generally speaking, the more long working life, management experience is rich, the greater the performance, 
so the experience management attaches great importance to the summary and accumulation of management experience.

\section{Conclusion}

In this paper, we research on the higher education management mode of China and abroad based on the novel perspective of operation mechanism and separation of school and the government. Due to the implementation of the compulsory higher education system, and to develop higher vocational and technical training, more socialized, diversified higher education phenomenon, has brought the higher education management is very complicated problem. Which makes the original experience in management and administrative management mode is more and more is more difficult to solve which is reasonable make full use of higher education resources management issues. Our research is focusing on the comparison and combination of the pattern. We firmly believe that the proposed methodology will enhance the current management model and enhance the higher education quality.

\section{References}

[1] Liu L N, Division P S. From Objective Management to Process

Management_-The Transition of Postgraduate Higher education Quality Management Mode[J]. Journal of Baicheng Normal University.

[2] Yufeng $\mathrm{M}$ A, Zhang $\mathrm{X}$, Jiang $\mathrm{H}$, et al. Exploration on graduates management mode of military medical universities[J]. Basic Medical Higher education, 2014.

[3] Cao S, Tang H. Teaching Platform Construction and Management Mode of Distance Higher education with the Aid of Mobile Technology[J]. Modern Distance Higher education Research, 2014. 